\title{
Sucking Method of Administration
}

National Cancer Institute

\section{Source}

National Cancer Institute. Sucking Method of Administration. NCI Thesaurus. Code C149961.

The technique of administration of a pharmaceutical product by placing it in the mouth and encouraging it to dissolve in the saliva, usually by moving the tongue. 